\title{
Sustaining Industry Leadership Through Technology Strategy Dimensions
}

\author{
Theuns G. Pelser, North-West University, South Africa
}

\begin{abstract}
Strategic management is inter alia a process of managing a company's relationship with the environment. A critical concern of this discipline is optimising returns to the company's stakeholders over the long term. This means sustaining performance by balancing strategic investments in technology with short-term profitability. The main purpose of this study was to investigate technology strategies in widespread use in technology intensive industries and to explore their relationship to company performance. A non-probability, judgment sample of companies listed on the Johannesburg Stock Exchange (JSE) were taken. The study makes a contribution to the field of strategic management research by integrating the dimensions of several previous studies, to derive a more comprehensive taxonomy of technology strategy archetypes. Two distinct technology factors obtained with the analysis were proved to positively influence the company performance dimensions and were classified as product development intensity and technology focus factors. The results show that strategy choices can significantly affect company performance. It thereby indicates which of the underlying dimensions have the strongest relationship with company performance. From an industry perspective, the greatest significance of these findings may be that they accentuate the importance of technology policy in strategic management. The substantial differences in performance associated with the dimensions do not necessarily indicate that a given company should choose a particular technology strategy, but rather indicates that technology policy decisions may have a substantial leverage on a company's performance and should be analysed and exercised with care and deliberation.
\end{abstract}

Keywords: Sustaining Industry Leadership; Technology Strategy Dimensions; Strategic Management

\section{INTRODUCTION}

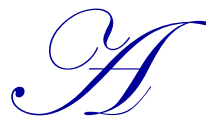

11 attempts to understand the effects of technological progress on economic growth, pay homage to Joseph Schumpeter (1961), an Austrian economist remembered for his views on the "creative destruction" associated with industrial cycles. Arguably, the most radical economist of the 20th century, Schumpeter was the first to challenge classical economics as it sought to optimise existing resources within a stable environment - treating any disruption as an external force on par with plagues, politics, and the weather. As Schumpeter saw it, a normal, healthy economy was not one in equilibrium but one that was constantly being "disrupted" by technological innovation (Reisman, 2008; Schumpeter, 1961).

International business literature suggests that companies develop competitive advantages in order to ensure success in current markets (Hamel \& Prahalad, 2006; Levitt, 1983; Ohmae, 1989; Panagiotou, 2007). Such advantages tend to be monopolistic assets, either tangible or intangible (Clemens, 2006), such as new technology, patented products, product development capability, and marketing skills. In a dynamic global market, companies that generate competitive advantages by effectively integrating research and development, production, and marketing activities, tend to ultimately succeed.

In order to acquire advantages, companies may develop technical knowledge from internal and/or external sources. Experience curve advantage may, therefore, be developed by companies that can successfully accumulate integrated knowledge in their business operations. Studies (e.g., by Pérez-Luñoa et al., 2011), have shown that one of the important factors for successful innovation, is good coupling among design, development, production, and 
marketing functions. Companies that fail to synthesise these functional activities, could result in business collapse (Ohmae, 1989). The importance of learning from technology has been emphasised by Freeman (1994). But, technical knowledge can hardly be obtained without the necessary processing and modification. Mature companies, especially, have difficulty adapting to changes in technology (Hamel \& Prahalad, 2006).

In coming years, the widely acknowledged importance of technology will grow, increasing the wager executives must place on their companies' ability to compete through technology (Shoham \& Fiegenbaum, 2002). The cutting edge of technology management, however, goes beyond basic research and development (R\&D) expenditures. Increasingly, corporate strategists are making a more precise distinction between "technology" and "technology management." Technology addresses the application of scientific and engineering knowledge to the solution of problems. Technology management, however, has a broader charter as it is the integration of technology throughout the organisation as a source of sustainable competitive advantage (Harmon \& Davenport, 2007). This particular study builds on the previous work of Pelser (2001, 2014a, 2014b, 2014c) regarding strategy taxonomies and their link to company performance.

\section{LITERATURE REVIEW}

A study that addresses company performance with the content dimensions of strategic management requires reviewing and analysing a large and diverse body of literature. It is impractical to attempt to discuss all of the research applicable to this topic. This section therefore, only reviews the pioneering research deemed most relevant to the present study. The number of dimensions used to develop strategy taxonomies and the variables required to describe them, have varied by researcher. However, the main thrust of these strategic dimensions is that companies often have a set of strategic goals for improved competitiveness, increased market share and to strengthened their strategic position (Dahan \& Shoham, 2014).

When Miller \& Friesen (1977) derived their strategy archetypes in the late 1970s, they gathered data on 31 variables representing four categories of adaptive behaviour (strategy dimensions). Galbraith \& Schendel (1983) gathered data on 26 variables using the PIMS (Profit Impact of Market Strategy) database. Snow \& Hrebiniak (1980) used a 145 item questionnaire to gather data that were subsequently reduced to ten distinctive competence variables and one performance ratio prior to analysis. Cool \& Schendel (1987) developed fifteen scope and resource commitment dimension variables, based on data drawn from a large variety of databases. Fiegenbaum \& Thomas (1990) used seven scope and resource deployment, and six performance variables. Zahra \& Covin (1993) used four dimensions to develop five business strategy taxonomies and three dimensions for technology strategy. Dvir et al., (1993) used Miles \& Snows' four strategy archetypes and two strategy variables.

\section{Technology Strategy Dimensions}

Technology policies encompass both the contents of technology strategies and the processes of technology management (Pelser, 2001). For this reason, technology strategy is operationalised in this study through the use of six content dimensions, which were derived from prior pioneer studies mentioned and used to guide the selection of the following twelve strategy variables to measure each dimension:

1. Technology Posture

- Striving for dominance in key technologies.

- Pursuing high-risk, break-through technologies resulting in a reputation for technical innovation.

2. Technology Level

- Hiring R\&D personnel with post-graduate degrees.

- Utilising state-of-the-art tools and facilities to push frontiers of technology development.

3. Technology Breadth

- Maintaining a broad in-house technology base.

- Utilising diverse technical reference resources.

4. Product Development Intensity

- Increasing total number of products offered.

- Continuously improving existing products. 
5. Technology Timing

- Being first to discover new technologies.

- Being first to introduce low cost or innovative products.

6. Manufacturing and Process Technology

- Use of technology to achieve low manufacturing costs or to manufacture unique products.

- Use of technology to improve production flexibility or reduce lead-times.

Technology Posture

Technology posture refers to a company's propensity to proactively use technology as a competitive weapon and a key-positioning factor (Zahra \& Covin, 1993). Therefore, the variables used to measure this dimension, relate to a company's propensity to accept technical risk (Rauch et al., 2009) and the extent to which reputation building is a conscious goal. In a global research study undertaken at Sloan School of Management and supported by the International Centre for Research in Management of Technology (ICRMOT), it was concluded, that technological advantage can be realised by effectively linking the technology strategy with overall corporate strategy and leveraging internal technology with an increasing number and variety of external technology sources (Roberts, 1989). Burgelman et al. (1996) and Song et al. (2013), view technological leadership in terms of the relative advantage in the command of technological competencies and capabilities, resulting from a commitment to a pioneering role in the development of a technology, as opposed to a more passive monitoring role.

Technology Level

Technology level refers to the sophistication of the technology employed by the company relative to current advancements of the particular technology (Maidique \& Patch, 1988; Miller, 1988; Clark et al., 1989). It is measured in the study in terms of the number of personnel with post-graduate degrees and the sophistication of the company's research tools and facilities. Technology is a human-created resource comprising various components, which enables a company to perform its productive activities. The key elements that influence the technology level of the company are the technology components available to the company and the technology capabilities possessed by the company. The enhancement of a company's competitive edge in the marketplace can be accomplished by increasing the advancement of the technology level added by the company's operations. This is achieved through the enhancement of the degree of sophistication of technology components utilised and the level of accumulation of technology capabilities (Sharif, 1997; Shoham \& Fiegenbaum, 2002). Hence, technological components enable desired transformation and technological capability of the company from performing activities over time and acquiring external resources; e.g., hiring R\&D personnel with post-graduate degrees.

\section{Technology Breadth}

Technology breadth refers to the number of technologies in which the company maintains competence (Dvir et al., 1993). It is measured in the study in terms of the extent of a company's in-house technology base and the diversity of their research references; i.e., intellectual property position. According to Zahra \& Hayton (2008) and Rauch et al. (2009), the breadth of a company's technology portfolio depends on the company's technology posture, risk orientation, environmental factors, financial resources, and the capacity to manage the technology portfolio's complexity. A broad portfolio of technologies enables a company to pursue many market opportunities, reduces its vulnerability to competitor's technologies, and sanctions it to take advantage of the convergence of different technologies in creating new markets. However, a broad portfolio of technologies can strain the company's organisation, resources, and management.

\section{Product Development Intensity}

Product development intensity refers to the number and rate of new product introductions (Miller, 1988; Clark et al., 1989; Dvir et al., 1993; Zahra \& Covin, 1993). It is measured in the study in terms of the emphasis on expanding the product line and the emphasis on introducing improved versions of existing products. According to Kleinschmidt (1994) and Ngamkroeckjoti et al. (2005), new product development (NPD) is critical to the growth and survival of modern companies. Numerous groups of factors that have an impact on new product development 
intensity have been identified in the literature. Having an explicit new product strategy, results in more successful NPD programmes, according to Dwyer (1990). However, Adler et al. (1989) found, that companies are reluctant to embark on the strategic management of new product development.

\section{Technology Timing}

Technology timing refers to a company's propensity to lead or follow competitors in introducing new products (Hung-Chia, 2013; Maidique \& Patch, 1988; Miller, 1988). It is measured in terms of the emphasis a company places on leading the competition in discovering new technologies, introducing products, employing new technologies, or introducing low cost products. A company may pioneer technological change in its industry or follow its competitors' lead (Song et al., 2013). Pioneering and followership represent the two endpoints of a continuum of technological postures, with points between these extremes reflecting different follower positions (Kerin et al., 1992). Pioneering indicates a company that leads its industry in creating technologies and which requires radical product innovations (Ali, 1994; Pérez-Luñoa et al., 2011). Companies often use pioneering offensively to capture premium segments, achieve economies of scale, set industry standards, or control distribution channels (Golder \& Tellis, 1993; Song et al., 2013).

\section{Manufacturing and Process Technology}

Manufacturing and process technology refer to the degree to which new technology is incorporated into the company's manufacturing plants and processes (Zahra \& Covin, 1993). It is measured in terms of the emphasis a company places on the use of technology to achieve low manufacturing costs or to manufacture unique products and to improve production flexibility or reduce lead-times. The proper manufacturing technologies can provide the company with considerable operational and competitive benefits (Sohal, 1995). According to Swann \& O'Keefe (1990), these include improvements in quality, inventory control, customer lead times, machine use and efficiency, staff efficiency, and customer image. Ensminger et al. (2004) points out, that technical success is often widely accepted as successful implementation. However, he observes that the prime motivation for investing in manufacturing and process technology is to improve company competitiveness. This competitiveness flows from gains in such system characteristics as responsiveness, quality, and flexibility. Therefore, technical success is a necessary, but not sufficient, condition for business success.

\section{Company Performance}

As mentioned in the introduction of this article, this particular study draws on the previous work of Pelser (2001, 2014a, 2014b, 2014c) regarding strategy taxonomies and their link to company performance for the independent variables.

Zahra \& Hayton (2008) established that the literature on performance is very extensive, but that it shows a lack of consensus as to the meaning of the term. Brush \& Vanderwerf (1992) point out, that the use of the term "performance" by researchers includes many constructs measuring alternative aspects of performance. This is consistent with the finding of Murphy et al. (1996) who, after a comprehensive literature review, were able to isolate a total of 71 different measures of performance. In spite of this apparent abundance, the vast majority of studies have used financial measures of performance (Murphy et al., 1996). The raison d'être for this fixation with financial performance measures, is found partly in the fact that financial performance is at the core of the organisational control systems and partly in that it is one of the most easily quantifiable measuring instruments. For example, Lussier (1995) argues, that in studying the benefits of technology, instead of analysing macro-economic data from governmental statisticians, micro-economic corporate financial results, certified by auditors, should be used. However, this has caused empirical research to rely on a narrow set of accounting measures of financial performance, such as return on investment (ROI), return on assets (ROA), or earnings per share (Pandian, et al., 2006; Sapienca et al., 1988).

When using accounting measures for measuring company performance, a number of issues should be taken into consideration. First, financial records are, in general, difficult to interpret, even if accurate financial data are reported (Cooper, 1979). Second, absolute numbers on financial performance criteria are affected by industryrelated factors (Miller \& Toulouse, 1986). Directly comparing financial data for companies in different industries 
could be misleading; even if the sample contains companies from the same industry sector, they may include companies operating in different markets. Third, accounting measures may be susceptible to accounting method variation, and lastly, accounting measures are not always representative of the actual performance of the companies, as many company directors for a variety of reasons manipulate performance reporting.

Despite the fact that financial performance is evidently important for the company, it draws only on the economic dimension of performance, neglecting other important goals of the company (Venkatramen \& Ramanjan, 1986). This argument is supported by Zahra \& Covin (1994), who argue that research that considers only a single performance dimension or a narrow range of performance constructs (e.g., multiple indicators of profitability), may result in misleading descriptive and normative theory building. According to the author of this study, it is unlikely that any single performance measure or dimension could serve the needs of a diverse set of research questions. This view is also shared by Zahra \& Hayton (2008), who points out, that a multi-dimensional construct provides an alternative in establishing valid operational definitions. Further to this, Murphy et al. (1996) argue, that a distinction between performance measures should be done on the grounds of whether the sources are secondary data (also known as archival) versus primary data (e.g., questionnaire interview).

The innovation management organisation (IMO) is responsible for developing new products and technologies (Pérez-Luñoa et al., 2011). Science and technology from the external environment are combined with the company's in-house skills, knowledge, and competencies to develop new products and technologies. The responsibilities that fall within the domain of innovation management encompass research and development (R\&D). For this reason, R\&D consists of those activities and responsibilities ranging from understanding progressive technology to generating ideas to developing new products and technologies. Understanding the dynamics of the innovation management organisation (IMO) is important to understanding the role and impact of strategic leadership of innovation in technology intensive companies. The conceptual definition is, therefore, the extent to which the R\&D manager or other top manager perceives that the IMO has achieved its desired objectives over the last three years.

\section{PROBLEM STATEMENT AND RESEARCH QUESTIONS}

The decline of USA industrial competitiveness in the 1970s and 1980s became a subject of increasing concern to people in education, industry, and government. Several initiatives were mounted to determine the sources of this decline and to formulate a successful response to the challenge presented. A consensus was reached on the idea that a significant amount of this effort had to be directed toward improving the management of technology. The decline of USA industry during those two decades is widely perceived to have resulted, not from an inability to develop new technologies, but from the failure to manage available and emerging technologies in an effective and timely manner.

Technology plays a pivotal role in interactions among the individual, society, and nature. Technological advances have major effects on each of these entities and are, in turn, influenced by them. As competitive pressures increase, the need to continuously adapt, develop, and innovate has become a basic building block for organisational excellence. Weaknesses to innovate, eventually lead businesses to stagnate and fade away in the face of a dynamic environment. There is a critical need to understand the key factors that lead to innovation excellence, the organisational and environmental innovation, and the importance of innovation strategies. The main purpose of this study is to investigate technology strategies in widespread use in technology intensive industries and to explore their relationship to company performance. The problem addressed in the study, is the need for a better understanding of the role that technology and innovation play in determining company performance. The study focuses on two central questions:

1. What is the prevalent technology strategy dimensions being employed by South African companies in technology intensive industries?

2. What relationships can be observed between the technology strategy dimensions and company performance? 


\section{RESEARCH METHODOLOGY}

The data gathering and analysis phase of the study adheres to the same methodology as applied by Pelser (2001, 2014a, 2014b, 2014c) regarding strategy taxonomies and their link to company performance and had the following three objectives:

1. Gathering data along key technology strategy dimensions from $R \& D$ managers of technology intensive companies.

2. Gathering objective data about the performance (input and output) of those companies selected for the study.

3. Analysing the data using multivariate statistical methods to explore the relationships among the technology strategy dimensions and company performance.

\section{Data Requirements}

The number of dimensions historically used to develop strategy taxonomies and the variables required to describe them, have varied by researcher. When Miller \& Friesen (1977) derived their strategy taxonomies in 1977, they gathered data on 31 variables representing four categories of adaptive behaviour (later classified as strategy dimensions). Galbraith \& Schendel (1983) gathered data on 26 variables using the PIMS database. Snow \& Hrebiniak (1980) used a 145 item questionnaire to gather data that were subsequently reduced to ten distinctive competence variables and one performance ratio prior to analysis. Cool \& Schendel (1987) developed 15 scope and resource commitment dimension variables based on data drawn from a large variety of databases. Fiegenbaum \& Thomas (1990) used seven scope and resource deployment dimensions and six performance variables that reduced to three performance ratios. Zahra \& Covin (1993) used four dimensions to develop five business strategy archetypes and three dimensions to represent technology strategy. Dvir et al. (1993) used Miles \& Snow's (1978) four strategy archetypes and two strategy variables.

As the body of strategic management research literature grows, authors of new studies who seek to develop strategy taxonomies are able to take advantage of prior research results to select proven more parsimonious sets of dimension variables. A benefit of parsimony is that the researcher must have a thorough a priori understanding of the data requirements set by the scope of the study. The data requirements for this study were developed by drawing on dimensions identified in prior technology strategy research. Initially, data were gathered along six technology strategy dimensions. The actual number of dimensions used to obtain technology strategy archetypes, were determined by the number of significant factors derived in the factor analysis.

Several of the pioneer studies on strategic taxonomies gathered research data in the form of management perceptions of their company's objectives or capabilities relative to some benchmark; e.g., the competition's objectives or capabilities. This is consistent with the method recommended by Galbraith \& Schendel (1983) and Panagiotou (2007), and is the method employed in the present study. This method also lends itself to answers that can be provided on a normalised five point Likert Scale, with "three" valued answers being "neutral" or "at the industry norm." The technology strategy dimensions are the result of a substantial body of prior research and include the key dimensions of technology strategy development. The dimensions pertaining to this study were derived from those most often cited in the literature and are a consolidation of the following studies: Maidique \& Patch (1988), Miller (1988), Clark et al. (1989), Dvir et al. (1993) and Zahra \& Covin (1993). Table 1 shows the published sources for the dimensions used in this study. The presence of an " $\mathrm{X}$ " in a cell indicates that the dimension identified in the column label was derived from the study identified in the row label. For example, the technology strategy dimension labelled "product development (PD) intensity," was derived from comparable dimensions found in four previous studies; i.e., Miller (1988), Clark et al. (1989), Dvir et al. (1993) and Zahra \& Covin (1993). 
Table 1: The Derivation of Technology Strategy Dimensions

\begin{tabular}{lcccccc}
\hline \multicolumn{1}{c}{ Authors } & $\begin{array}{c}\text { Technology } \\
\text { Posture }\end{array}$ & $\begin{array}{c}\text { Technology } \\
\text { Level }\end{array}$ & $\begin{array}{c}\text { Technology } \\
\text { Breadth }\end{array}$ & PD Intensity & $\begin{array}{c}\text { Technology } \\
\text { Timing }\end{array}$ & $\begin{array}{c}\text { Process } \\
\text { Technology }\end{array}$ \\
\hline Maidique \& Patch & & $\mathrm{X}$ & & & $\mathrm{X}$ & X \\
Miller & & $\mathrm{X}$ & $\mathrm{X}$ & $\mathrm{X}$ & \\
Clark, Ford \& Saren & & $\mathrm{X}$ & $\mathrm{X}$ & $\mathrm{X}$ & \\
Dvir, Segev \& Shenhar & $\mathrm{X}$ & & $\mathrm{X}$ & \\
Zahra \& Covin (1993) & $\mathrm{X}$ & & & $\mathrm{X}$ \\
\hline
\end{tabular}

A survey of R\&D managers of companies listed on the Johannesburg Stock Exchange (JSE) was conducted through the use of a questionnaire. The South African context was chosen both from an operational purpose and the objective to compare the findings with those obtained from studies conducted in other countries or regions. Since the performance of companies in technology intensive industries could be more affected by technology policies than by the performance of companies in other industries, it was assumed that companies in technology industries would be more likely to have technology strategies, thereby making it easier to observe the relationships of interest.

R\&D managers from 200 South African technology intensive companies were asked to complete a selfadministered electronic questionnaire designed to gather data regarding their company's technology policies. The questionnaire requested data on the specific industry in which the company operates the technology and innovation strategy of the company and the processes the company employs to develop and implement the strategy. Eighty-four valid responses were ultimately received and used in the study.

Previously published research reports were used to identify a set of technology strategy, technology management, and innovation strategy dimensions (refer to Table 1). Each dimension measured through the use of two items in the questionnaire. The questionnaire items were designed to permit answers on a five-point interval or Likert Scale. Thirty variables were used to gather data on fifteen dimensions. A survey questionnaire was developed and tested in a small pilot study in order to assess the clarity of the directions and questionnaire items. It was then revised and submitted to five technology strategists to confirm its intelligibility and cognitively confirm the validity of the study dimensions and variables as relating to important factors in strategic management of technology.

A number of company performance dimensions were used as the dependent variables in the analysis of the study. Despite the fact that financial performance is evidently important for the company, it draws only on the economic dimension of performance, neglecting other important goals of the company. This argument is supported by Zahra \& Covin (1994) and Pandian et al. (2006), who argues that research that considers only a single performance dimension or a narrow range of performance constructs (e.g., multiple indicators of profitability), may result in misleading descriptive and normative theory building. Hansen (2010) and Murphy et al. (1996) pointed out, that it is unlikely that any single performance measure or dimension could serve the needs of a diverse set of research questions. The selection of the company performance dimensions resulted in six dependent variables. These six variables were classified in the following two dimension groups.

- $\quad$ Effectiveness of the IMO - (4 input dependent variables).

- $\quad$ Performance of the company - (2 output dependent variables).

The measures selected for this study, demonstrate strong relationships with company performance and had been reviewed in the literature section:

1. Contribution to sales (i.e., right product at the right time).

2. Efficiency of innovation project management (i.e., project success rate).

3. Impact of the innovations (e.g., degree of novelty or technical impact).

4. $\quad R \& D$ expenditure (i.e., investment in $R \& D$ activities).

5. Patent information (i.e., output of R\&D activities).

6. Return on assets (i.e., company financial performance). 
Factor analysis was used to reduce the dimensions into identifiable factors. Pearson r-correlation was then used to find the strength and direction of the relationships between the factors and the performance dimensions. The relationships examined, are those between the independent variables and the effectiveness of the innovation management organisation (IMO) and the performance of the company.

\section{Sample Selection}

A non-probability, judgment sample of companies listed on the Johannesburg Stock Exchange (JSE) was taken. It was decided to use listed companies on the JSE for two primary reasons: (1) Listed companies display a capacity and capability (capital and human resources) for R\&D activities compared to smaller unlisted companies. (2) Quantifiable data (e.g., annual reports) is more readily available for the external stakeholders of listed companies than it is on unlisted companies. The motivation for using the judgment method in sampling was to build a database of those companies most likely to be associated with manufacturing products and/or investing in R\&D activities. Based on the abovementioned screening criteria, it was decided to use the Industrial Consumer sector.

The following two important criteria were established to select the appropriate companies or divisions within the Industrial Consumer sector for the study:

1. New product development activities, which included tangible as well as intangible products; e.g., computer software.

2. Contact details for the R\&D manager or designated top manager responsible for research and development; e.g., Technical Director.

Two hundred companies or divisions were identified and incorporated in the survey after the screening stage. Feedback was received from 89 R\&D managers of these two hundred companies, stating their willingness to participate in the survey. A total of 84 completed responses were received and captured for the study. This translates to a 42 percent response rate from the base of 200 originally identified companies. However, compared to the feedback received from the 89 respondents, it effectively means, that the filtered response rate equates to 94 percent. The non-response portion of the original sample of 200 companies is comprised of 64 companies. An additional 24 companies have indicated that they are not involved in any type of R\&D activities, which automatically excluded them from the study. Another 23 companies provided feedback or reasons concerning their non-participation in the survey, which ranges from vacant positions in R\&D key functions to a lack of interest of these type of research efforts.

A breakdown of the respondents per industry is presented in Figure 1. Compared to the other sectors, technological opportunities are higher in science based sectors: chemicals, oils and plastics; electronic and electrical; IT, and telecommunications. These companies also emphasise more on product innovation than process innovation and represent 58 percent of the respondents. 


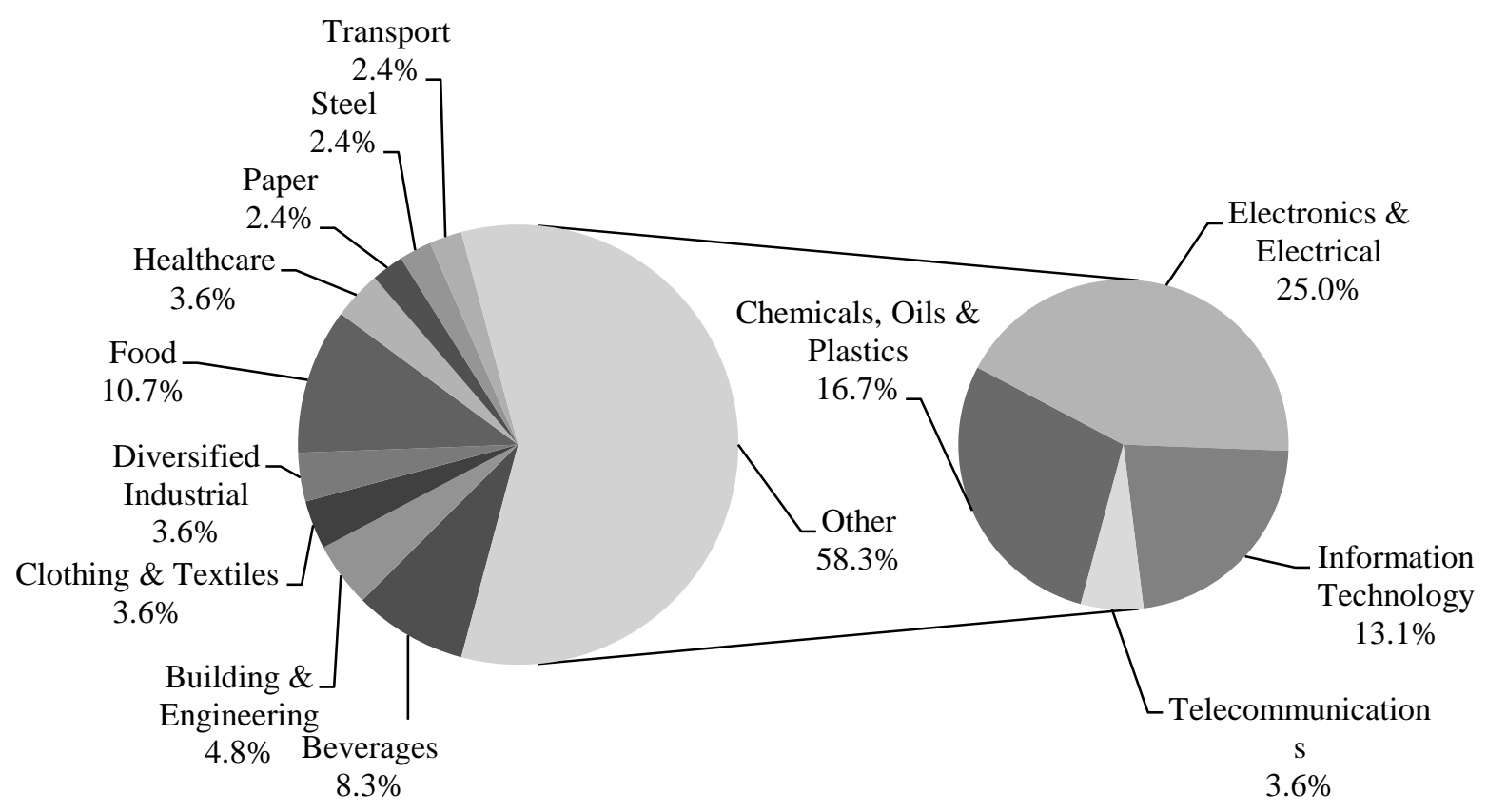

Figure 1: Surveyed Companies by Industry

\section{ANALYSIS OF RESULTS}

\section{Descriptive Statistics: Technology Strategy Dimensions}

The descriptive statistics of central tendency and measures of variability for the technology strategy dimensions are shown for variables A1 - A12 in Table 1. No missing values $(\mathrm{N})$ were encountered with the data capturing process. The range corresponds to the numerical value of 4 . The minimum value (substantially less) equals 1 and the maximum value (substantially more) equals 5 . Although the values assigned to this set of responses run from 1 through 5 and, therefore, form an ordinal scale, they are considered to be interval-scaled under the assumption that the respondents had treated the differences between adjacent response categories to be equal. Numbers forming an interval scale, permit one to compute measures of central tendency (also known as elevation how high or how low the scores on a question tend to be) by calculating the mean (arithmetic average). The highest mean response turns out to be 3.80 for variables A5, A7, and A8. For example, the arithmetic average of the responses for variable $\mathrm{A} 8$ indicate, that the sample of companies continuously improve existing products somewhat more than do their competitors. The lowest mean response turns out to be 3.05 for variable A12. This indicates that the sample is at the same level as their competitors, when it comes to being first to introduce low cost or innovative products. The largest standard deviation is 1.39 from variable A11. Therefore, it can be concluded, that the sample is relatively homogenous and consequently, the mean gives a good indication of the responses. The skewness measures obtained for the technology strategy variables, point to negatively skewed distributions (values smaller than 0) for all the variables, except for variable A12. Only variable A5 falls outside the -1 range, which designates a substantially skewed distribution. All of the variables, except for variable A5, have flat distributions, as is shown by their kurtosis values in Table 2. 
Table 2: Descriptive Statistics - Technology Strategy Dimensions

\begin{tabular}{|c|c|c|c|c|c|c|c|c|c|c|c|c|}
\hline \multirow{2}{*}{ Variable } & \multirow{2}{*}{$\mathbf{N}$} & \multirow{2}{*}{ Range } & \multirow{2}{*}{ Min } & \multirow{2}{*}{ Max } & \multicolumn{2}{|c|}{ Mean } & \multirow{2}{*}{$\begin{array}{c}\text { Std. } \\
\text { Deviation }\end{array}$} & \multirow{2}{*}{ Variance } & \multicolumn{2}{|c|}{ Skewness } & \multicolumn{2}{|c|}{ Kurtosis } \\
\hline & & & & & Statistic & Std Error & & & Statistic & Std Error & Statistic & Std Error \\
\hline$\overline{\mathrm{A} 1}$ & 84 & 4.00 & 1.00 & 5.00 & 3.5595 & .1470 & 1.3475 & 1.816 & -.689 & .263 & -.662 & .520 \\
\hline $\mathrm{A} 2$ & 84 & 4.00 & 1.00 & 5.00 & 3.5238 & .1462 & 1.3396 & 1.795 & -.822 & .263 & -.490 & .520 \\
\hline A3 & 84 & 4.00 & 1.00 & 5.00 & 3.3452 & .1295 & 1.1872 & 1.409 & -.263 & .263 & -.795 & .520 \\
\hline A4 & 84 & 4.00 & 1.00 & 5.00 & 3.5714 & .1271 & 1.1646 & 1.356 & -.365 & .263 & -.710 & .520 \\
\hline A5 & 84 & 4.00 & 1.00 & 5.00 & 3.7976 & .1276 & 1.1697 & 1.368 & -1.028 & .263 & .493 & .520 \\
\hline A6 & 84 & 4.00 & 1.00 & 5.00 & 3.6310 & .1405 & 1.2874 & 1.657 & -.628 & .263 & -.703 & .520 \\
\hline A7 & 84 & 4.00 & 1.00 & 5.00 & 3.7976 & .1342 & 1.2299 & 1.513 & -.637 & .263 & -.688 & .520 \\
\hline A8 & 84 & 4.00 & 1.00 & 5.00 & 3.7976 & .1133 & 1.0388 & 1.079 & -.308 & .263 & -.573 & .520 \\
\hline A9 & 84 & 4.00 & 1.00 & 5.00 & 3.2143 & .1222 & 1.1201 & 1.255 & -.384 & .263 & -.079 & .520 \\
\hline A10 & 84 & 4.00 & 1.00 & 5.00 & 3.5357 & .1179 & 1.0805 & 1.167 & -.623 & .263 & -.036 & .520 \\
\hline A11 & 84 & 4.00 & 1.00 & 5.00 & 3.2857 & .1520 & 1.3934 & 1.941 & -.146 & .263 & -1.280 & .520 \\
\hline A12 & 84 & 4.00 & 1.00 & 5.00 & 3.0476 & .1208 & 1.1075 & 1.227 & .013 & .263 & -.595 & .520 \\
\hline
\end{tabular}

\section{Descriptive Statistics: Company Performance Dimensions}

The descriptive statistics of central tendency and measures of variability for the company performance dimensions are shown for variables B31 - B36 in Table 3. No missing values (N) were encountered with the data capturing process. The range for variables B31 - B34 is 5. The values assigned to this set of responses, run from 1 through 6 and, therefore, form an ordinal scale. However, variables B35 - B36 conforms to all the properties of the previously mentioned scales. These quantified responses form a ratio scale, which is defined as a set of numbers in which the ratios between numbers can be meaningfully interpreted (Parasuraman et al., 2007). Two measures of central tendency are meaningful for the ordinal-scaled responses (B31 - B34): the mode as a number depicting the "middle" position in the range of responses and the median, that is, the category in which the 50th percentile response falls when all responses are arranged from lowest to highest (or vice versa). Referring to Table 3 , variable B31 realised a mode of $2(10-24 \%)$ for the percentage of sales over the last three years, due to new products. The percentage of innovation projects that earned a profit over the last three years (variable B32) corresponds to the response option (1) of less than 10\%. The same mode applies to variable B33 (innovations as new-to-the-world breakthroughs) and B34 (R\&D expenditure as a percentage of sales) for a rank order of less than $10 \%$. The quantified responses to variables B35 and B36 are classified as metric data on the ratio scale. The mean for the three-year-average number of patents registered (variable B35) per year, is 2.45 patents, with a high standard deviation of 3.42. However, the most frequently recurring response (mode) was 0 patents reported by respondents. The mean for the company's three-year-average return on assets (variable B36) is 21.24 percent. Multiple modes have been calculated for variable B36 and for that reason, no mode is indicated. If the calculated values of skewness and kurtosis exceed a critical value, then the distribution is non-normal. A value exceeding \pm 2.58 indicates that the assumption about the normality of the distribution at the .01 probability level can be rejected. At the .05 error level, the critical value is \pm 1.96 . All the above mentioned variables (A1 - B36) are within the limits of the critical values, thus indicating normality (Hair et al., 2010).

Table 3: Descriptive Statistics - Company Performance Dimensions

\begin{tabular}{|c|c|c|c|c|c|c|c|c|c|c|c|c|}
\hline \multirow{2}{*}{ Variable } & \multirow{2}{*}{$\mathbf{N}$} & \multirow{2}{*}{ Range } & \multirow{2}{*}{ Min } & \multirow{2}{*}{ Max } & \multirow{2}{*}{$\begin{array}{c}\text { Mean } \\
\text { Statistic }\end{array}$} & \multirow{2}{*}{$\begin{array}{c}\text { Std } \\
\text { Deviation }\end{array}$} & \multirow{2}{*}{ Median } & \multirow{2}{*}{ Mode } & \multicolumn{2}{|c|}{ Skewness } & \multicolumn{2}{|c|}{ Kurtosis } \\
\hline & & & & & & & & & Statistic & Std Error & Statistic & Std Error \\
\hline B31 & 84 & 5.00 & 1.00 & 6.00 & 2.9167 & 1.4579 & 3.00 & 2.00 & .483 & .263 & -.858 & .520 \\
\hline B32 & 84 & 5.00 & 1.00 & 6.00 & 2.7143 & 1.4106 & 3.00 & 1.00 & .394 & .263 & -.792 & .520 \\
\hline B33 & 84 & 5.00 & 1.00 & 6.00 & 2.2024 & 1.4790 & 2.00 & 1.00 & 1.084 & .263 & -.074 & .520 \\
\hline B34 & 84 & 5.00 & 1.00 & 6.00 & 2.0238 & 1.2319 & 2.00 & 1.00 & 1.142 & .263 & .337 & .520 \\
\hline B35 & 84 & 14.00 & .00 & 14.00 & 2.4524 & 3.4165 & .00 & .00 & 1.316 & .263 & .872 & .520 \\
\hline B36 & 84 & 62.00 & -15.00 & 47.00 & 21.2381 & 12.3255 & 22.50 & Multiple & -.548 & .263 & .118 & .520 \\
\hline
\end{tabular}

\section{Descriptive Statistics: Change Affecting Factors}

In considering which factor affects change in a company's particular industry, variable B37 was used to measure the respondents' choices. Looking at Table 4, it is noticeable that two factors are representing 60 percent of the respondents' choices. Technology and external changes were selected as change affecting factors by 31 and 29 percent of the 84 respondents respectively. 
Table 4: Change Affecting Factors

\begin{tabular}{lcccc}
\hline \multicolumn{1}{c}{ Variable B37 } & Frequency & Percent & Valid Percent & Cumulative Percent \\
\hline Target markets & 7 & 8.3 & 8.3 & 8.3 \\
Technology & 26 & 31.0 & 31.0 & 39.3 \\
Product features & 1 & 1.2 & 1.2 & 40.5 \\
Manufacturing methods & 8 & 9.5 & 9.5 & 50.0 \\
Product lines & 13 & 15.5 & 15.5 & 65.5 \\
External changes & 24 & 28.6 & 28.6 & 94.0 \\
Other & 5 & 6.0 & 6.0 & 100.0 \\
Total & 84 & 100.0 & 100.0 & \\
\hline
\end{tabular}

Twenty-eight respondents indicated that target markets ( 8 percent), manufacturing methods (10 percent) and product lines (16 percent) were the most important factors affecting change in their industries. Product features and other change factors, received only 7 percent of the respondents' choices. Figure 2 provides a graphical illustration of these results.

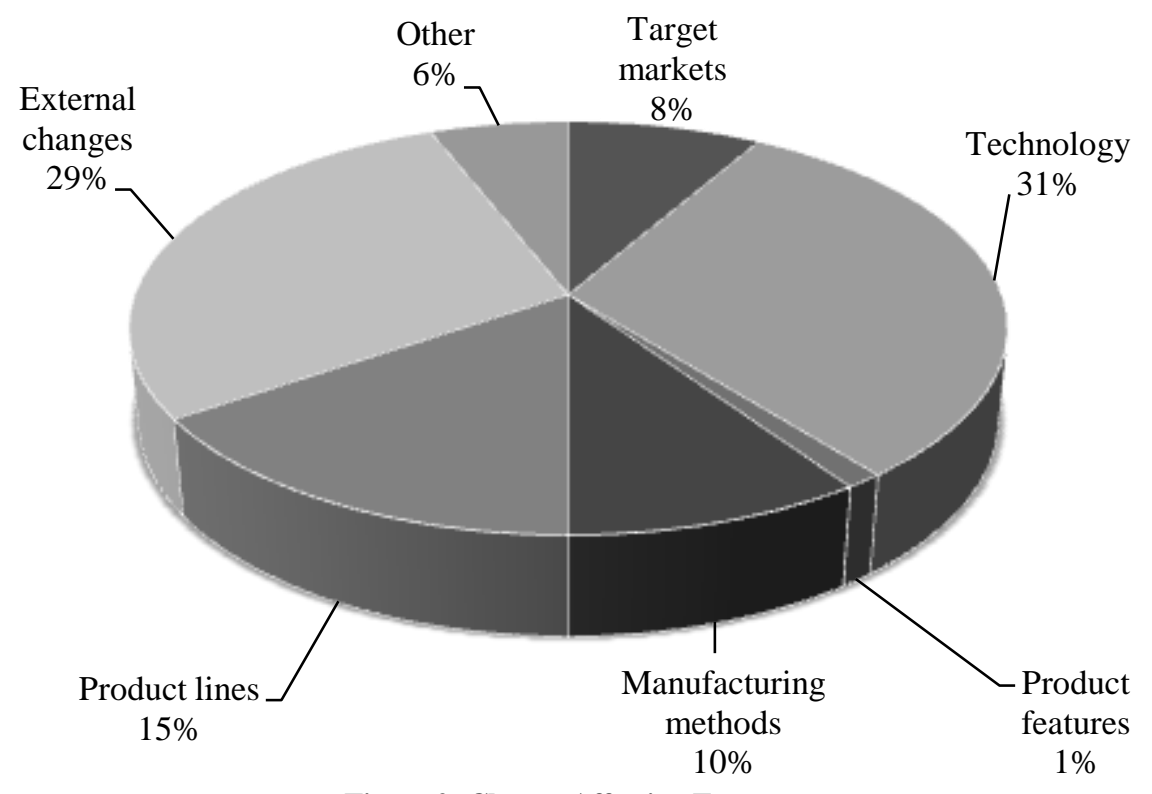

Figure 2: Change Affecting Factors

\section{Factor Analysis: Technology Strategy}

An attempt was made to factor analyse the twelve original strategy variables (A1 - A12). However, a negative error variance (Heywood case) was encountered with the initial variable set. Heywood cases are a common type of offending estimate, which occurs when the estimated error term for an indicator becomes negative. According to Hair et al. (2010), the problem is remedied either by deleting the indicator or by constraining the measurement error value to be a small positive value. The first alternative is the preferred action prescribed by the authors. Therefore, variables A11 and A12 were deleted from the current technology strategy factor analysis. These two variables were later re-classified under the technology management dimension. The remaining ten strategy variables (A1 - A10) were factor analysed by using the principal axis factoring method. Then using the latent root criterion, two factors were extracted on the basis of the scree plot. Together they accounted for 70.25 percent of the variation in the data. The factors were rotated by using the Varimax rotation method and then used as inputs for the regression and cluster analysis.

The correlation matrix for the ten strategy variables was reviewed to confirm the existence of a substantial number of correlations, which indicates the existence of common factors. All the variables had correlations greater than .22 and almost 60 percent of the matrix elements were greater than .50 . Bartlett's test of sphericity confirmed, 
that the correlation matrix was not an identity matrix. The Kaiser-Meyer-Olsen (KMO) measure as sampling adequacy was .778, which Hair et al. (2010) characterised as "middling," indicating that the degree of correlation between unique factors was low. The anti-image covariance matrix contained few elements with values greater than 0.9 , again confirming the applicability of factor analysis.

The number of factors to be extracted was initially set at three, based on the Kaiser criterion of selecting factors with Eigenvalues greater than 1. This was confirmed by a scree test, which displayed a knee, followed by a flat line after the third factor. However, this resulted in an invalid (values greater than 1) communality requiring the deletion of the third factor for the purposes of the study. The Chi-square statistic was 702.763 with 47 degrees of freedom, which is significant at the .000 level. The reduced set of variables collectively meets the necessary threshold of sampling adequacy and thus the fundamental requirements for factor analysis. The final statistics showed, that 70.25 percent of the variance was explained by the two factors. The reproduced correlation matrix contained 18 residual values ( 40 percent) greater than .05 , indicating that the model fits the data.

The rotated strategy factor loadings are contained in Table 5. As a reminder, each survey respondent was asked to report on the importance of each of the variables to his or her company relative to major competitors. The heaviest factor loading for each variable is formatted in bold font style.

Table 5: Rotated Technology Strategy Factor Matrix

\begin{tabular}{|c|c|c|c|}
\hline Variable & Variable Description & Factor 1 & Factor 2 \\
\hline A2 & Pursuing high-risk, break-through technologies & .934 & .244 \\
\hline A1 & Striving for dominance in key technologies & .898 & .180 \\
\hline A4 & Utilising state-of-the-art tools and facilities & .807 & .347 \\
\hline A5 & Maintaining a broad in-house technology base & .684 & .288 \\
\hline A3 & Hiring R\&D personnel with advanced degrees & .620 & .457 \\
\hline A9 & Being first to discover new technologies & .586 & .203 \\
\hline A6 & Utilising diverse technical reference resources & .564 & .369 \\
\hline A10 & First to introduce low cost or innovative products & .550 & .153 \\
\hline A7 & Increasing total number of products offered & .168 & .973 \\
\hline A8 & Continuously improving existing products & .361 & .735 \\
\hline
\end{tabular}

All of the primary factor loadings used in the factor interpretation exceeded .50 in value. According to Hair et al. (2010), factor loadings greater than \pm .30 are considered to meet the minimal level; loadings of \pm .40 are considered important; and if the loadings are \pm .50 or greater, they are considered more important. Considering the factor loadings, the rotated factors are interpreted below and visually displayed in Figure 3.

1. Technology Focus - The Eigenvalue of the first factor was 5.643. The technology posture variables (A1 A2), technology level variables (A3 - A4), technology breadth variables (A5 - A6) and the technology timing variables (A9 - A8) loaded heavily on this factor. Taken together, this pattern of factor loadings clearly reflects the aggressiveness of a company's technology policy.

2. Product Development Intensity - The Eigenvalue of the second factor was 1.708. The two product development variables (A7 - A8) both loaded heavily on this factor. The product development intensity variables were selected to measure the extent to which a company competes on the basis of frequent new product introductions and frequent product upgrades. 


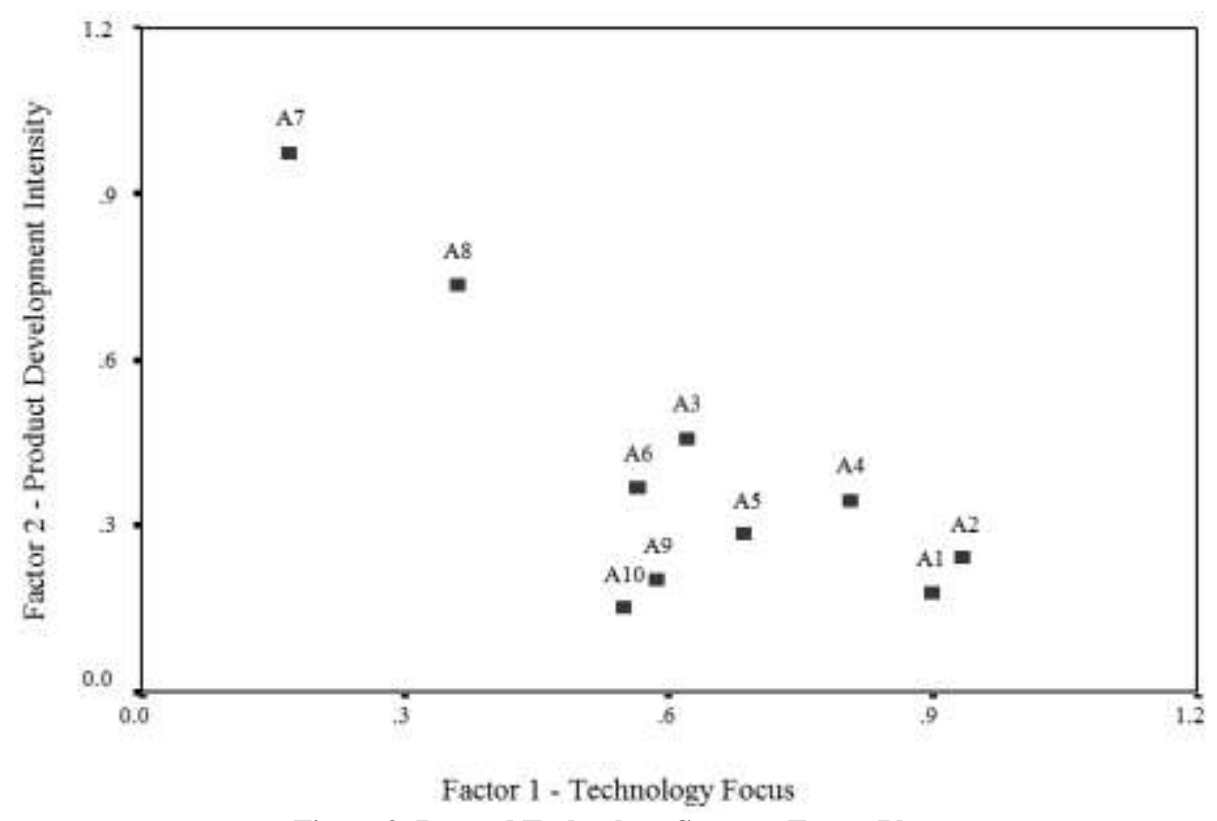

Figure 3: Rotated Technology Strategy Factor Plot

\section{Factor Analysis: Company Performance}

The methodology for factor analysing the dependent variables, was similar to that used for the previous sections. The six company performance variables (B31 - B36) were factor-analysed by using the principal axis factoring method. Then, using the latent root criterion, two factors were extracted on the basis of their Eigenvalues being greater than 1 . Together they accounted for 75.80 percent of the variation in the data. The factors were rotated by using Varimax rotation method. The same number of methods was used to determine the appropriateness of a factor-analytic model for this analysis.

The correlation matrix for the six company performance variables was reviewed to confirm the existence of a substantial number of correlations, which indicates the existence of common factors. All the variables had correlations greater than .16 and more than 40 percent of the matrix elements were greater than .50 . Bartlett's test of sphericity confirmed, that the correlation matrix was not an identity matrix. The Kaiser-Meyer-Olsen (KMO) measure as sampling adequacy was .791, which Hair et al. (2010) characterised as "middling." This is also defined as an adequate measure, indicating that the degree of correlation between the unique factors was low. The antiimage covariance matrix contained no elements with values greater than 0.9 , again confirming the applicability of factor analysis.

Based on the Kaiser criterion of selecting factors with Eigenvalues greater than 1, the number of factors to be extracted, were set at two. However, the scree test indicates that three factors would be retained. In combining these two criteria, two factors were eventually retained for further analysis, because of the very low Eigenvalue (.538) for the third factor. The Chi-square statistic was 235.832 with 15 degrees of freedom, which is significant at the .000 level. The reduced set of variables collectively meets the necessary threshold of sampling adequacy and thus the fundamental requirements for factor analysis.

The final statistics showed, that 75.80 percent of the variance was explained by the two factors. The reproduced correlation matrix contained 3 residual values ( 20 percent) greater than .05 , indicating that the model fits the data. The rotated company performance factor loadings are contained in Table 6 . The heaviest factor loading for each variable is formatted in bold font style. As a reminder, each respondent was asked to respond to the following questions. 
B31 - Approximately what percentage of sales over the last three years was due to new products?

B32 - Approximately what percentage of innovation projects over the last three years earned a profit?

B33 - Approximately what percentage of innovations over the last three years could be considered new-to-the-world breakthroughs?

B34 - What is your three-year-average R\&D expenditure as a percentage of sales?

B35 - What is your three-year-average number of patents registered per year?

B36 - What is your company or division's three-year-average ROA?

Table 6: Rotated Company Performance Factor Matrix

\begin{tabular}{lcccc}
\hline & Variable & Variable Description & Factor 1 & Factor 2 \\
\hline B32 & Efficiency of innovation project management & $\mathbf{. 8 4 1}$ & .308 \\
B33 & Impact of the innovations & $\mathbf{. 7 9 7}$ & .213 \\
B31 & New product contribution to sales & $\mathbf{. 7 7 3}$ & .188 \\
B34 & R\&D expenditure & $\mathbf{. 7 5 6}$ & .123 \\
B35 & Patents registered & .089 & .762 \\
B36 & Return on assets & .308 & $\mathbf{. 6 1 9}$ \\
\hline
\end{tabular}

All of the primary factor loadings used in the factor interpretation, exceeded .50 in value. Considering the factor loadings, the rotated factors are interpreted below and visually displayed in Figure 4.

1. Input Performance - The conceptual definition for this factor is the extent to which the R\&D manager or other top manager perceives the innovation management organisation has achieved its desired objectives over the last three years. The Eigenvalue of the first factor was 3.167. The four input variables (B31 - B34) loaded heavily on this factor. Taken together, this pattern of factor loadings clearly reflects the effectiveness of the innovation management organisation (IMO).

2. Output Performance - This factor represents the performance of the company where (1) patent information was used to measure R\&D activities and (2) return on assets (ROA) was used to measure company financial performance. The Eigenvalue of the second factor was 1.381. The patent's registered variable (B35) and the return on assets variable (B36) loaded heavily on this factor, indicating the degree of fit for this performance measure.

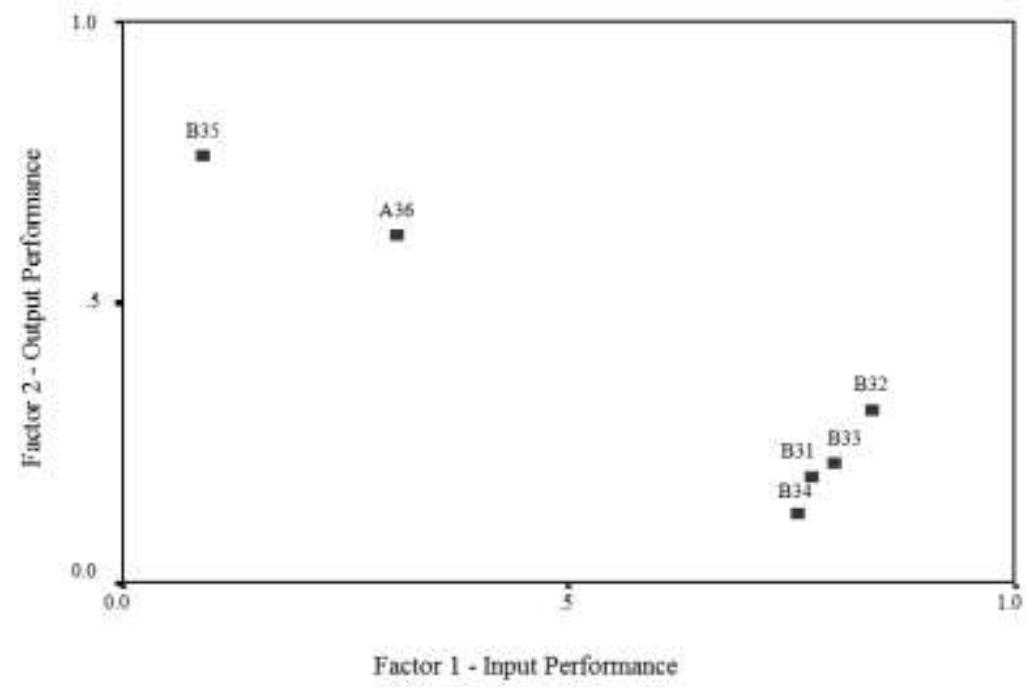

Figure 4: Rotated Company Performance Factor Plot

\section{Reliability and Validity}

The data analysis proceeds by evaluating the survey responses according to the four dimensions for validity and reliability. The summated scales of the study provide two specific benefits. First, it provides a means of overcoming the measurement error inherent in all measured variables. A second benefit of the summated scale is its 
ability to represent the multiple aspects of a concept in a single measure; e.g., the technology focus factor. However, four issues basic to the construction of any summated scale must be addressed before applying them (Hair et al., 2010).

Content validity is the first issue, which subjectively assesses the correspondence between individual items and the concept through ratings by expert judges, pre-tests, and other means. Content validity of the questions was obtained from the pilot study and the cognitive confirmation from the five technology experts. The second issue, which is validated by the high factor loadings (greater than 0.5) of the extracted factors, concerns the test of unidimensionality. According to Anderson et al. (1987), each summated scale should consist of items loading highly on a single factor.

The third issue concerns the degree of consistency between multiple measurements of a variable, known as reliability. The consistency of the survey data was assessed by using Cronbach's coefficient alpha, which measure the consistency of the entire scale. The Cronbach alpha computations for the nine extracted factors are shown in Table 7. For the technology focus coefficient, alpha is .9159; for the product development intensity it is .8685; for the process management it is .8826 , and for the input performance it is .8887 . These high values indicate a high degree of data stability.

Table 7: Reliability Analysis

\begin{tabular}{|c|c|c|c|c|c|}
\hline Variable & $\begin{array}{l}\text { Scale Mean if } \\
\text { Item Deleted }\end{array}$ & $\begin{array}{l}\text { Scale Variance if } \\
\text { Item Deleted }\end{array}$ & $\begin{array}{c}\text { Corrected Item } \\
\text { Total Correlation }\end{array}$ & Alpha if Item Deleted & Alpha \\
\hline \multicolumn{6}{|c|}{ Technology Focus (TF) } \\
\hline A1 & 24.6190 & 42.6483 & .8570 & .8929 & \multirow{8}{*}{.9159} \\
\hline $\mathrm{A} 2$ & 24.6548 & 41.9637 & .9096 & .8878 & \\
\hline A3 & 24.8333 & 46.6466 & .7085 & 9062 & \\
\hline A4 & 24.6071 & 45.0366 & .8415 & .8955 & \\
\hline A5 & 24.3810 & 46.7929 & .7114 & .9060 & \\
\hline A6 & 24.5476 & 46.9013 & .6231 & .9138 & \\
\hline A9 & 24.9643 & 48.9746 & .5943 & .9149 & \\
\hline A10 & 24.6429 & 50.1360 & .5387 & .9187 & \\
\hline \multicolumn{6}{|c|}{ Product Development Intensity (PDI) } \\
\hline A7 & 3.7976 & 1.0790 & .7785 & - & \multirow{2}{*}{.8685} \\
\hline A8 & 3.7976 & 1.5128 & .7785 & - & \\
\hline \multicolumn{6}{|c|}{ Process Management (PM) } \\
\hline A11 & 3.0476 & 1.2266 & .8108 & - & \multirow{2}{*}{.8826} \\
\hline A12 & 3.2857 & 1.9415 & .8108 & - & \\
\hline \multicolumn{6}{|c|}{ Input Performance (InP) } \\
\hline B31 & 6.9405 & 13.3820 & .7446 & .8617 & \multirow{4}{*}{.8887} \\
\hline B32 & 7.1429 & 13.0637 & .8234 & .8305 & \\
\hline B33 & 7.6548 & 13.1685 & .7540 & .8584 & \\
\hline B34 & 7.8333 & 15.1044 & .7130 & .8741 & \\
\hline \multicolumn{6}{|c|}{ Output Performance (OutP) } \\
\hline B35 & 21.2381 & 151.9185 & .5015 & - & \multirow{2}{*}{.4104} \\
\hline B36 & 2.4524 & 11.6724 & .5015 & - & \\
\hline
\end{tabular}

Looking at Table 7, it is evident that the output performance factor coefficient alpha is only .4104. However, the data accuracy aspect of reliability can be tested by comparing the test data with external criteria that measure the same variable. In this study the self-reported company return on asset variable (B36) was compared with published financial data from various sources (I-Net Bridge, company reports, etc.). Sixty-seven of 84 respondents correctly reported the return on asset (ROA) category. Fourteen cases exaggerated their ROA by one category and the remaining three cases diminished their ROA by one category. Three Chi-square-based measures of association were calculated; i.e., the phi coefficient, the coefficient of contingency and Cramer's V. Their respective values were $1.26, .63$, and .78. All were significant at the .00000 level (rounded to the fifth decimal place), indicating a strong relation between the reported and actual ROA data. These factors point to an acceptably high degree of data reliability. 
The fourth and final dimension for validity and reliability concerns construct validity. Construct validity is concerned with the question of what the research instrument is, in fact, measuring. Common factor analysis is one of the methods of analysing construct validity. The factor analysis found relatively high degrees of communality among the variables. Most of the dimension variables have communalities greater than 0.5 . The clear patterns of the factor loadings on the variables further validated the content and process constructs.

\section{Multiple Regression Analysis}

To ascertain the relative importance of the factors in explaining the variation in the dependent variables, multiple regression analysis was used to analyse the relationship between the dependent variables and independent variables. The objective of multiple regression analysis is to use the independent variables (three factors) whose values are known to predict the single dependent values (two performance factors). The Pearson r-correlations were calculated to find the strength and direction of the relationships between the factors and the performance dimensions. By using p-values, it was possible to distinguish between the levels of significance. From Table 8 the null-hypothesis was rejected $(\mathrm{p}<0.05$ or $\mathrm{p}<0.01)$ for all the factor correlations except for the Process Management factor $(\mathrm{p}>0.05$ or $\mathrm{p}>0.01)$.

Table 8: Correlation Matrix

\begin{tabular}{|c|c|c|c|c|c|c|}
\hline & \multicolumn{5}{|c|}{ 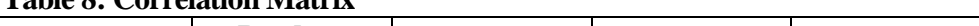 } \\
\hline & & $\begin{array}{l}\text { Technology } \\
\text { Focus }\end{array}$ & $\begin{array}{c}\text { Product } \\
\text { Development } \\
\text { Intensity } \\
\end{array}$ & $\begin{array}{c}\text { Process } \\
\text { Management }\end{array}$ & $\begin{array}{c}\text { Input } \\
\text { Performance }\end{array}$ & $\begin{array}{c}\text { Output } \\
\text { Performance }\end{array}$ \\
\hline \multirow{3}{*}{ Technology Focus } & Pearson Correlation & 1.000 & $.568 * *$ & .039 & $.698 * *$ & $.634 * *$ \\
\hline & Sig. (2-tailed) & . & .000 & .727 & .000 & .000 \\
\hline & $\mathrm{N}$ & 84 & 84 & 84 & 84 & 84 \\
\hline \multirow{3}{*}{$\begin{array}{l}\text { Product Development } \\
\text { Intensity }\end{array}$} & Pearson Correlation & $.568 * *$ & 1.000 & -.020 & $.510 * *$ & $.577 * *$ \\
\hline & Sig. (2-tailed) & .000 & 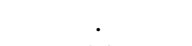 & .853 & .000 & .000 \\
\hline & $\mathrm{N}$ & 84 & 84 & 84 & 84 & 84 \\
\hline \multirow{3}{*}{ Process Management } & Pearson Correlation & .039 & -.020 & 1.000 & -.195 & -.030 \\
\hline & Sig. (2-tailed) & .727 & .853 & . & .075 & .788 \\
\hline & $\mathrm{N}$ & 84 & 84 & 84 & 84 & 84 \\
\hline \multirow{3}{*}{ Input Performance } & Pearson Correlation & $.698 * *$ & $.510 * *$ & -.195 & 1.000 & $.435 * *$ \\
\hline & Sig. (2-tailed) & .000 & .000 & .075 & . & .000 \\
\hline & $\mathrm{N}$ & 84 & 84 & 84 & 84 & 84 \\
\hline \multirow{3}{*}{ Output Performance } & Pearson Correlation & $.634 * *$ & $.577 * *$ & -.030 & $.435 * *$ & 1.000 \\
\hline & Sig. (2-tailed) & .000 & .000 & .788 & .000 & . \\
\hline & $\mathrm{N}$ & 84 & 84 & 84 & 84 & 84 \\
\hline
\end{tabular}

** Correlation is significant at the 0.01 level (2-tailed). * Correlation is significant at the 0.05 level (2-tailed).

It is apparent that both the technology focus and product development intensity factors have a significant positive effect on input and output performance.

\section{LIMITATIONS ON THE RESEARCH}

This study confines its focus to the effects of technology policy on company performance. In so doing, a number of other factors which affect company performance are omitted; e.g., marketing strategy, financial structure, culture, human resources, etc. The study was also restricted to South African listed companies in the Industrial Consumer sector on the Johannesburg Stock Exchange. Finally, the study is also limited to Return on Assets (ROA) as a financial measure of company performance.

\section{RECOMMENDATIONS}

The technology focus factor concerns the role that technology policy plays in the formulation and implementation of business strategies. Technology policies encompass both the contents of technology strategies and the processes of technology management. This factor comprises technology posture, technology level, technology breadth, and technology timing. This research indicates that technology policy plays a key role in the formulation and implementation of business strategies. It is recommended that companies use technology 
proactively as a competitive weapon and a key-positioning factor. Furthermore, that these companies should accept technical risk, increasing the sophistication of technology components utilised and the number of technologies in which the company maintains competence.

The product development intensity factor indicates the extent to which a company competes on the basis of frequent new product introductions and frequent product upgrades. New product development (NPD) is critical to the growth and survival of modern companies, due to shortening product life cycles. New products are representing a larger proportion of company sales for successful companies, compared to companies with an average or belowaverage performance. It is recommended that companies should expand existing product lines and introduce improved versions of existing products to sustain industry leadership.

The effectiveness of the innovation management organisation (IMO) is reflected in the input performance dimension. This dimension was derived from four distinct performance measures, which demonstrated strong relationships with company performance. Another recommendation is that the IMO focuses on frequent new product introductions and frequent product upgrades, with the emphasis placed on expanding existing product lines and by introducing improved versions of existing products. The activities associated with this product development intensity factor, are contained within the R\&D, production and sales \& marketing functions; the latter function being primarily responsible for interfacing between the company and the marketplace for introducing new or upgraded products.

Finally, the role of the top manager in technology intensive industries has become much more multidimensional. This is recognized by assigning both the technology focus (TF) to the top manager and top management team functions. This function is responsible for the formal technology policy within the company, with the objective to manage technical risk, increasing the sophistication of technology components utilised and the number of technologies in which the company maintains competence. Furthermore, they should be conscientious with encouraging researcher empowerment, the vast integration of R\&D with the company's business units and a high level of R\&D investment.

\section{CONCLUSION}

Strategic management is inter alia a process of managing a company's relationship with the environment. A critical concern of this discipline is optimising returns to the company's stakeholders over the long term. This means sustaining performance by balancing strategic investments in technology with short-term profitability.

The main purpose of this study was to investigate technology strategies in widespread use in technology intensive industries and to explore their relationship to company performance. In essence, the following two research questions were addressed in this study.

1. What is the prevalent technology dimensions being employed by South African companies in technology intensive industries?

2. What relationships can be observed between the technology dimensions and company performance?

Question one was addressed through factor analysing the technology strategy dimensions obtained from the survey. The second question was answered by regression analysis. The two distinct technology factors obtained with the analysis were proved to positively influence the company performance dimensions and were classified as product development intensity and technology focus factors.

The present study makes a contribution to the field of strategic management research by integrating the dimensions of several previous studies, to derive a more comprehensive taxonomy of technology strategy archetypes. It also derives a broader set of dimensions for use in strategic management research. The results show that strategy choices can significantly affect company performance. It thereby indicates which of the underlying dimensions have the strongest relationship with company performance.

There are many directions in which this research can be extended in both depth and breadth. For example, the number of companies surveyed, could be expanded (e.g., from local to international, listed to unlisted, high- 
technology to low-technology) to allow for greater control of the many exogenous variables (e.g., size, stage of industry life cycle, degree of alignment between the company's strategies, and the environment), which affect the relationship between strategy and company performance.

From an industry perspective, the greatest significance of these findings may be that they accentuate the importance of technology policy in strategic management. The substantial differences in performance associated with the dimensions do not necessarily indicate that a given company should choose a particular technology strategy, but rather indicates that technology policy decisions may have a substantial leverage on a company's performance and should be analysed and exercised with care and deliberation.

\section{AUTHOR INFORMATION}

Prof. Theuns Pelser is the Director and Strategy Professor of the Graduate School of Business and Government Leadership, North-West University, Mafikeng Campus. Prior to this appointment he was Strategy Manager at Sasol, a petro-chemical multinational company. He holds a $\mathrm{PhD}$ in Strategic Management from the Potchefstroom University. His research focuses on technology strategies, innovation strategies and technology management processes and their relationship to company performance. Theuns Pelser, Graduate School of Business and Government Leadership, North-West University, South Africa. E-mail: theuns.pelser@nwu.ac.za

\section{REFERENCES}

1. Adler, P. S. (1989). Technology strategy: guide to the literature. In R. S. Rosenbloom \& R. A. Burgelman (eds.), Research on technological innovation, management and policy. Greenwich, CT: JAI Press.

2. Ali, A. (1994). Pioneering versus incremental innovation: Review and research propositions. Journal of Product Innovation Management, 11(1) 46-61.

3. Anderson, J. C., Gerbing, D. W., \& Hunter, J. E. (1987). On the assessment of unidimensional measurement: Internal and external consistency and overall consistency criteria. Journal of Marketing Research, 24(November), 432-437.

4. Brush, C. G., \& Vanderwerf, P. A. (1992). A comparison of methods and sources for obtaining estimates of new venture performance. Journal of Business Venturing, 7(2) 157-170.

5. Burgelman, R. A., Maidique, M. A., \& Wheelwright, S. C. (1996). Strategic management of technology and innovation (2nd ed.). New York: McGraw-Hill.

6. Clemens, C. (2006). Monopolistic competition and entrepreneurial risk-taking. Economics Letters, 93(1), 68-74.

7. Clark, K., Ford, D., \& Saren, M. (1989). Company technology strategy. R\&D Management, 19(3), 215229.

8. Cool, K. O., \& Schendel, D. E. (1987). Strategic group formation and performance: the case of the U.S. pharmaceutical Industry, 1963-1982. Management Science, 33(9), 1102-1124.

9. Cooper, A. C. (1979). Strategic management: new ventures and small business. In D. E. Schendel \& C. W. Hofer (eds.), Strategic management: A new view of business policy and planning. Boston, MA: Little Brown.

10. Dahan, G., \& Shoham, A. (2014). Strategic orientations: Developing an integrative model of pioneering, entrepreneurial, and stakeholder orientations. Procedia - Social and Behavioral Sciences, 109, 758-762.

11. Dvir, D., Segev, E., \& Shenhar, A. (1993). Technology's varying impact on the success of strategic business units with the Miles and Snow typology. Strategic Management Journal, 14(2), 155-162.

12. Dwyer, L. M. (1990). Factors affecting the proficient management of product innovation. International Journal of Technical Management, 5(6), 721-730.

13. Ensminger, D. C., Surry, D. W., Porter, B. E., \& Wright, D. (2004). Factors contributing to the successful implementation of technology innovations. Educational Technology \& Society, 7(3), 61-72.

14. Fiegenbaum, A., \& Thomas, H. (1990). Strategic groups and performance: The US insurance industry, 1970-1984. Strategic Management Journal, 11(3), 197-216.

15. Freeman, C. (1994). The economics of technical change. Cambridge Journal of Economics, 18(5), 463514. 
16. Galbraith, C., \& Schendel, D. (1983). An empirical analysis of strategy types. Strategic Management Journal, 4(2), 153-173.

17. Golder, P. N., \& Tellis, G. J. (1993). Pioneer advantage: marketing logic or marketing legend? Journal of Marketing Research, 30(2), 158-170.

18. Hair, J. F. Jr., Black, W. C., Babin, B. J., \& Anderson, R. E. (2010). Multivariate data analysis: A global perspective $\left(7^{\text {th }}\right.$ ed.). Upper Saddle River: Pearson Prentice Hall.

19. Hansen, A. (2010). Nonfinancial performance measures, externalities and target setting: A comparative case study of resolutions through planning. Management Accounting Research, 21(1), 17-39.

20. Hamel, G., \& Prahalad, C. K. (2006). The core competence of the corporation strategic learning in a knowledge economy. In D. Hahn \& B. Taylor (eds.), Strategische Unternehmungsplanung - Strategische Unternehmungsführung. Berlin, Heidelberg: Springer.

21. Harmon, P., \& Davenport, T. (2007). Business process change ( $2^{\text {nd }}$ ed.). Burlington, MA: Morgan Kaufmann.

22. Hung-Chia, S. H. (2013). Technology timing of IPOs and venture capital incubation. Journal of Corporate Finance, 19(1), 36-55.

23. Kerin, R. A., Varadarajan, P. R., \& Peterson, R A. (1992). First-mover advantage: a synthesis, conceptual framework and research propositions. Journal of Marketing, 56(4), 33-52.

24. Kleinschmidt, E. J. (1994). A comparative analysis of new product programmes: European versus North American companies. European Journal of Marketing, 28(7), 5-29.

25. Levitt, T. (1983). The globalisation of markets. Harvard Business Review, 61(3), 92-102.

26. Lussier, R. N. (1995). A non financial business success versus failure prediction model for young firms. Journal of Small Business Management, 33(1), 8-20.

27. Maidique, M. A., \& Patch, P. (1988). Corporate strategy and technological policy. In M. L. Tushman \& W. L. Moore (eds.), Readings in the management of innovation (2nd ed.). Cambridge, MA: Ballinger.

28. Miles, R. E., \& Snow, C. C. (1978). Organisational strategy, structure and process. New York: McGrawHill.

29. Miller, A. (1988). A taxonomy of technological settings with related strategies and performance levels. Strategic Management Journal, 9(3), 239-254.

30. Miller, D., \& Friesen, F. (1977). Archetypes of strategy formulation. Management Science, 24(9), 921-933.

31. Miller, D., \& Toulouse, J. M. (1986). Strategy, structure, CEO personality and performance in small firms. American Journal of Small Business, 10(3), 47-62.

32. Murphy, G. B., Trailer, J. M., \& Hill, R. C. (1996). Measuring performance in entrepreneurship research. Journal of Business Research, 36(1), 15-23.

33. Ngamkroeckjoti, C., Speece, M., \& Dimmitt, N. J. (2005). Environmental scanning in Thai food SMEs: The impact of technology strategy and technology turbulence. British Food Journal, 107(5), 285-305.

34. Ohmae, K. (1989). Managing in a borderless world. Harvard Business Review, 67(3), 152-161.

35. Panagiotou, G. (2007). Reference theory: strategic groups and competitive benchmarking. Management Decision, 45(10), 1595-1621.

36. Pandian, J. R, Thomas, H., Furrer, O., \& Bogner, W. C. (2006). Performance differences across strategic groups: An examination of financial market-based performance measures. Strategic Change, 15(6), 373383.

37. Parasuraman, A., Grewal, D., \& Krishnan, R. (2007). Marketing research (2nd ed.). Boston, MA: Houghton Mifflin Harcourt.

38. Pelser, T. G. (2001). A strategic management taxonomy of technology and innovation. (Unpublished PhD thesis). Potchefstroom: Potchefstroomse Universiteit vir Christelike Hoër Onderwys.

39. Pelser, T. G. (2014a). The influence of technology strategies and their link to company performance. Mediterranean Journal of Social Sciences, 5(6), (no page numbers yet).

40. Pelser, T. G. (2014b). The affect of innovation strategies and their connect to company performance. Mediterranean Journal of Social Sciences, 5(6) (no page numbers yet).

41. Pelser, T. G. (2014c). Sustaining industry leadership through innovation strategy archetypes. International Business \& Economics Research Journal, 13(4), (no page numbers yet). 
42. Pérez-Luñoa, A., Wiklundb, J., \& Cabrera, R. A. (2011). The dual nature of innovative activity: How entrepreneurial orientation influences innovation generation and adoption. Journal of Business Venturing, 26(5), 555-571.

43. Rauch, A., Wiklund, J., Freese, M., \& Lumpkin, T. (2009). Entrepreneurial orientation and business performance: Cumulative empirical evidence. Entrepreneurship Theory and Practice, 33(3), 761-779.

44. Reisman, D. (2008). Schumpeter on the economics of innovation and Heertje's. Research in the History of Economic Thought and Methodology, 26(1), 235-254.

45. Roberts, E. B. (1989). The personality and motivations of technological entrepreneurs. Journal of Engineering and Technology Management, 6(1), 5-23.

46. Sapienza, H. J., Smith, K. G., \& Gannon, M. J. (1988). Using subjective evaluations of organizational performance in small business research. American Journal of Small Business, 12(3), 45-53.

47. Schumpeter, J. A. (1961). The theory of economic development: An inquiry into profits, capital, credit, interest, and the business cycle. New Brunswick: Transaction Publishers.

48. Sharif, M. N. (1997). Technology strategy in developing countries: evolving from comparative to competitive advantage. International Journal Technology Management, 14(2-4), 309-43.

49. Shin, J., \& Lee, H. (2013). Low-risk opportunity recognition from mature technologies for SMEs. Journal of Engineering and Technology Management, 30(4), 402-418.

50. Shoham, A., \& Fiegenbaum, A. (2002), Competitive determinants of organisational risk-taking attitude: the role of strategic reference points. Management Decision, 40(2), 127-141.

51. Snow, C. C., \& Hrebiniak, L. G. (1980). Strategy, distinctive competence and organisational performance. Administrative Science Quarterly, 25(2), 317-336.

52. Sohal, A. (1995). Assessing implementations: An empirical field study. Proceedings of the 1995 European Conference on Management of Technology. Birmingham, 469-484.

53. Song, M., Zhao, Y. L., \& Di Benedetto, C. A. (2013). Do perceived pioneering advantages lead to firstmover decisions? Journal of Business Research, 66(8), 1143-1152.

54. Swann, K., \& O’Keefe, W. D. (1990). Advanced manufacturing technology: investment decision process. Management Decision, 28(3), 27-34.

55. Zahra, S. A. (1996). Technology strategy and financial performance: Examining the moderating role of the firm's competitive environment. Journal of Business Venturing, 11(3), 189-219.

56. Zahra, S. A., \& Covin, J. (1993). Business strategy, technology policy and firm performance. Strategic Management Journal, 14(6), 451-478.

57. Zahra, S. A., \& Covin, J. (1994). The financial implications of fit between innovation types and sources and competitive strategy. Journal of High Technology Management Research, 5(2), 183-212.

58. Zahra, S. A., \& Hayton, J. C. (2008). The effect of international venturing on firm performance: The moderating influence of absorptive capacity. Journal of Business Venturing, 23(2), 195-220. 